\section{The emergence of cooking in Southwest Asia Katherine Wright}

There has been surprisingly little systematic study by prehistorians of how in the distant past people cooked and consumed food. There are many unanswered questions. For example, how did cooking emerge and affect human evolution, how did it change with the advent of farming, when did kitchens first appear and who built the earliest known ovens? Research on Palaeolithic and Neolithic food preparation and consumption is now beginning to suggest answers to such questions.

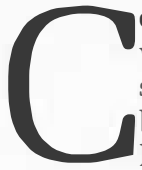

ooking and dining, together with the ability to create and use symbols, distinguish human beings from other creatures, but ittle is known about the earliest technology and social behaviour associated with these activities. The research described here is part of a project concerned with the evolution and social significance of early prehistoric cooking and dining technologies in Southwest Asia. My interest in this topic grew out of earlier research on common but little studied food-processing artefacts such as groundstone pounding and milling tools, and now encompasses a wider range of artefacts and features associated with food preparation, especially hearths and other fire features.

\section{What is cooking?}

The anthropologist Claude Levi-Strauss asserted that human beings transform nature into culture by cooking: raw food is nature, cooked food culture. ${ }^{2}$ Cooking opens up unlimited possibilities for new cultural rules. Furthermore, dining turns culture (food) into social life (meals), whereas cuisine changes meals into feasts, social life into hierarchy. ${ }^{3}$ Cooking is defined here as any tradition in which heat is used, at least sometimes, in food preparation. Thus, it implies the use of any combination of food-preparation techniques, provided that one of them is heating. In this article the focus is on techniques used relatively close to the time and place of consumption, so some activities involved in producing food, such as harvesting and winnowing grain, are not included. Techniques of food preparation vary enormously, but most can be grouped into four broad types of procedure: changing the physical structure of a food; using liquids but not heat; drying and applying dry heat; and applying liquids and heat together. ${ }^{4}$

Archaeological analysis offood customs involves the examination of the technological capacities of relevant artefacts and features such as stone tools and hearths; the spatial organization of food-preparation activities in archaeological sites; plant and animal remains; and human skeletons. It is essential to analyze variations in the construction and form of fire features. ${ }^{5}$ It is also important to remember that the functions of tools and features associated with other purposes too, such as heating and

Fire and hearth: the Palaeolithic food preparation need not have been used only for foods but are likely to have served craft production origins of cooking

Some food-preparation technologies of Homo sapiens appear to have evolved gradually from two million years ago until about 12,750 BC (all dates cited are in calibrated radiocarbon years BC). There are controversial hints of possible fire control by Homo erectus in the Lower Palaeolithic, ${ }^{6}$ but unambiguous fire features first appear in the Middle Palaeolithic, in association with Homo neanderthalensis in Europe, archaic Homo sapiens in Africa and both in Southwest Asia. ${ }^{7}$ The Middle Palaeolithic features are often simple flat fireplaces or firepits, but occasionally they are pit hearths with stone borders at the top or rim, or with fills containing small pebbles and fire-cracked rocks. Pebble borders and fills could have been used for blocking drafts, for supporting items to be heated, or for heating pebbles and moving them to containers or even the insides of whole animals. ${ }^{8}$

There is little dramatic change in the

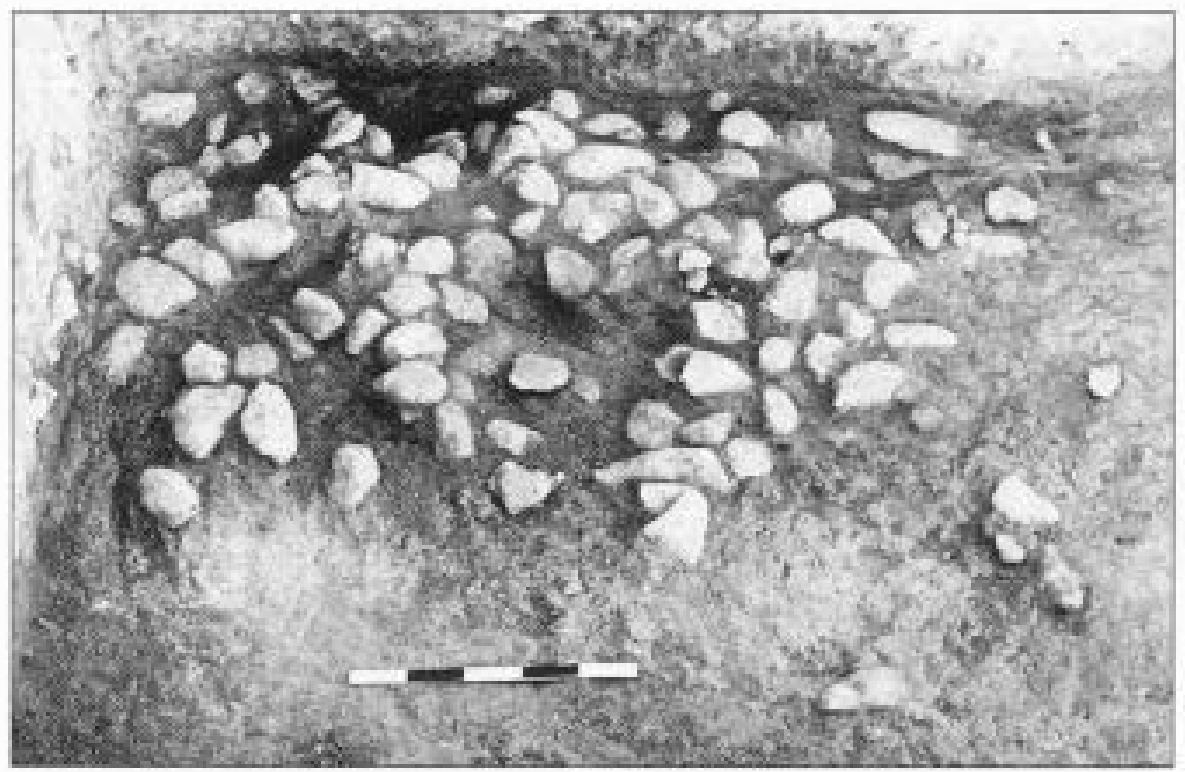

Figure 1 A pebble-filled pit hearth from the Early Epipalaeolithic site of Uwaynid 18 in eastern Jordan (scale bar $50 \mathrm{~cm}$ ). time. At these sites, carefully arranged basic technologies of groundstone artefacts and hearth construction from the Middle to the Upper Palaeolithic, but these artefacts and features appear more often and in larger numbers. The range of variation in the physical construction of individual hearths in the Upper Palaeolithic is somewhat greater than in the Middle Palaeolithic, from firepatches to stone-bordered or pebble-filled pit hearths (as at the c. 22,000-year-old site of Uwaynid 18 in Jordan, Fig. 1). ${ }^{9}$

In the Upper Palaeolithic there are indications that, at some sites, social groups larger than those of the Middle Palaeolithic may have engaged in cooking at the same clusters or lines of fire features are frequently present. For example, at $\mathrm{Abu}$ Noshra I in the southern Sinai, there are four stone-bordered fireplaces and pit hearths and one very large firepit that contained only bones of wild ass, which is interpreted as evidence for the animal having been roasted whole. ${ }^{10}$

These patterns hint at more structured cooperation and coordination of cooking and food sharing by larger groups, which would have encouraged more rapid transmission of cultural information. We cannot be certain that multiple hearths were used contemporaneously. But even if they were established at different times, by the end of these occupations hunter-gatherers would have had available to them a larger set of on-site cooking facilities than we see in most Middle Palaeolithic camp sites. People living at sites with multiple hearths would have been able to produce more prepared food at one time. Thus, the evidence from Southwest Asia possibly supports the idea that large-scale cooking (or feasting) ${ }^{11}$ first took place at such Upper Palaeolithic sites. ${ }^{12}$

Arrangements for cooking appear to 


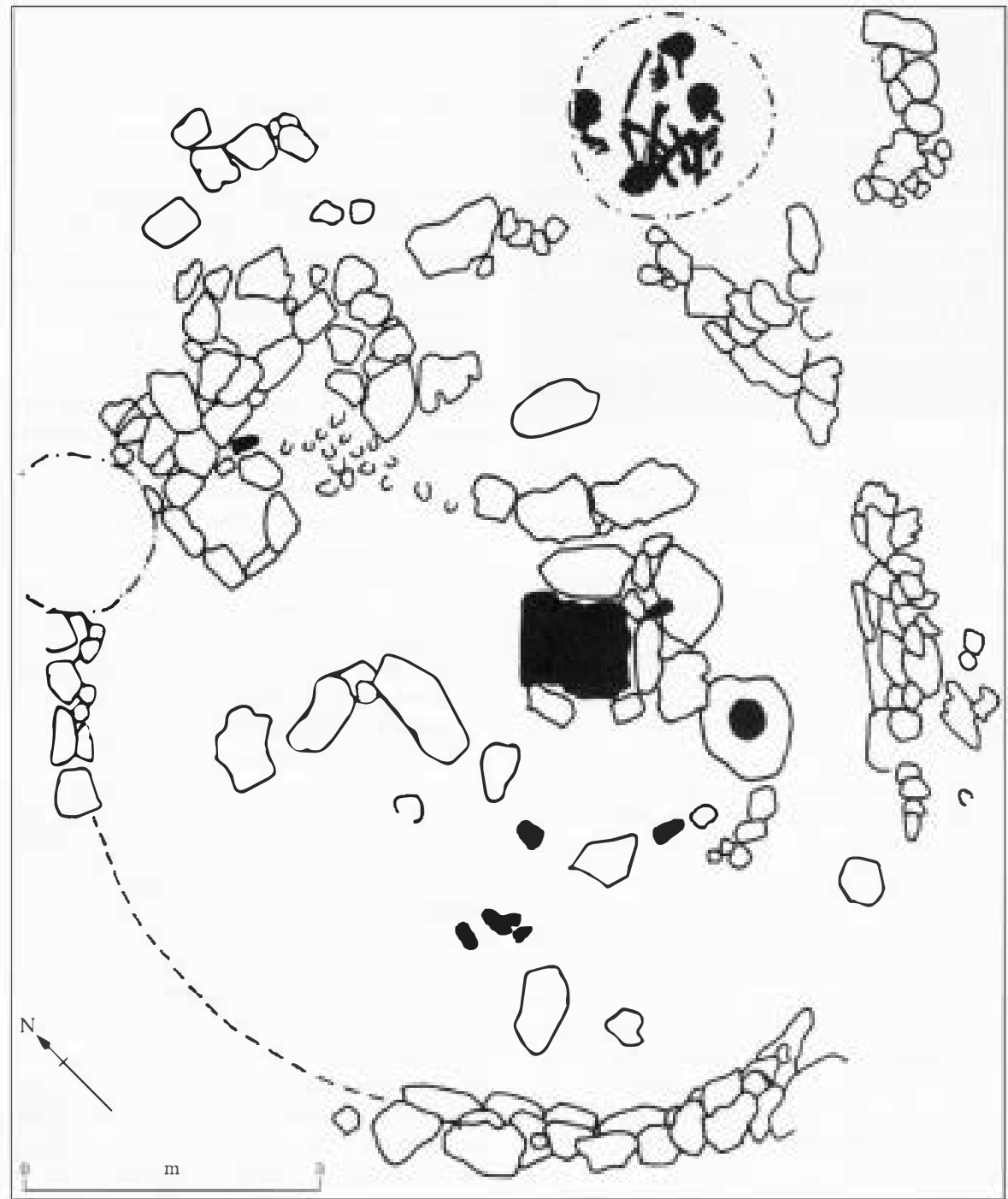

Figure 2 A Natufian house (no. 26) at 'Ain Mallaha, Israel(redrawn from Perrot 1966, n. 17). The black features consist of a rectangular hearth in the centre; a large boulder mortar south of the hearth, with its circular use-surface shown in black; groundstone artefacts, mainly pestles, west of the hearth and boulder; and a burial just outside the structure on the eastern side.

become more spatially structured in Early Epipalaeolithic sites between 21,750 and $12,750 \mathrm{BC}$. The most striking technological change is the appearance of mortars with deep grinding holes and elongated pestles. ${ }^{13}$ Thus, at Ein Gev I in Israel, evidence was found of a hut that had been repeatedly occupied, with a simple hearth in the middle of the floor and two pestles and a large stone mortar close by, evidently cached there as site furniture. ${ }^{14}$ Similar features, including a stone worktable, were found at Ohalo II in Israel. ${ }^{15}$ In these sites, as in earlier ones, the features and artefacts associated with cooking and dining that have been preserved look remarkably utilitarian. There is no indication that they were decorated or otherwise constructed for purposes of conspicuous display. This situation changes at the beginning of the Natufian (Late Epipalaeolithic) period about $12,750 \mathrm{BC}$
Overall, the Late Epipalaeolithic groundstone technology suggests a new formality in food sharing and an element of social ritual surrounding it (Fig. 3). What underlay this development? Most scholars agree that Natufian base camps represent settlements that were occupied year-round, while foraging territories were becoming quite restricted. ${ }^{19}$ This situation would have interfered with the classic means of conflict resolution practised by mobile hunter-gatherers, namely fission (i.e. the departure of one party to the conflict to other foraging territories). In short, because Natufian groups were more sedentary than earlier hunter-gatherers, they had to find other means of social integration. It seems likely that social rules surrounding food consumption grew more formalized in order to enhance social cohesion.

Feasting may have been part of this process, although we have no direct evidence for it. Settings for eating and drinking undoubtedly varied according to season and occasion, and areas where food was prepared have been found in both houses and outdoor contexts. Because base camps were probably occupied year-round, we can infer that in winter or bad weather some cooking and dining took place under shelter. Natufian houses never exceeded $28 \mathrm{~m}^{2}$ in area, so indoor processing and cooking could have involved only a few individuals. Sets of mortars and pestles found in pairs in caches suggest either that two people were involved in pounding and mixing foodstuffs or that pounded foods were deemed to require two separate sets. ${ }^{20}$

\section{Simple tastes: cooking and dining} in the PPNA

By the Pre-Pottery Neolithic A (PPNA) period $(10,050-9000 \mathrm{BC})$, there is evidence for domesticated barley and wheat at a few sites, indicating that the transition from foraging to farming was under way. With rare exceptions, PPNA groundstone artefacts utterly lack the diversity, workmanship and decoration that characterized the Natufian. The same is true of hearths, which were often merely areas of ash or burnt stones. Clearly, a different set of attitudes to food and dining were at work. The PPNA villagers seem to have had no interest in conspicuous displays in preparing and serving food. Despite the profound economic changes that accompanied the so-called agricultural revolution, cultural practices surrounding meals seem to have been remarkably undramatic.

There are at least three possible reasons for this: the medium of decoration or display may have been perishable materials rather than stone; other items of material culture, such as figurines or human skulls, may have been used to convey social messages at meals; simplicity may have been regarded as the proper aesthetic of cooking and dining. But storage features are likely to be a partial exception to the pattern. Stone-lined bins, which are relatively rare 


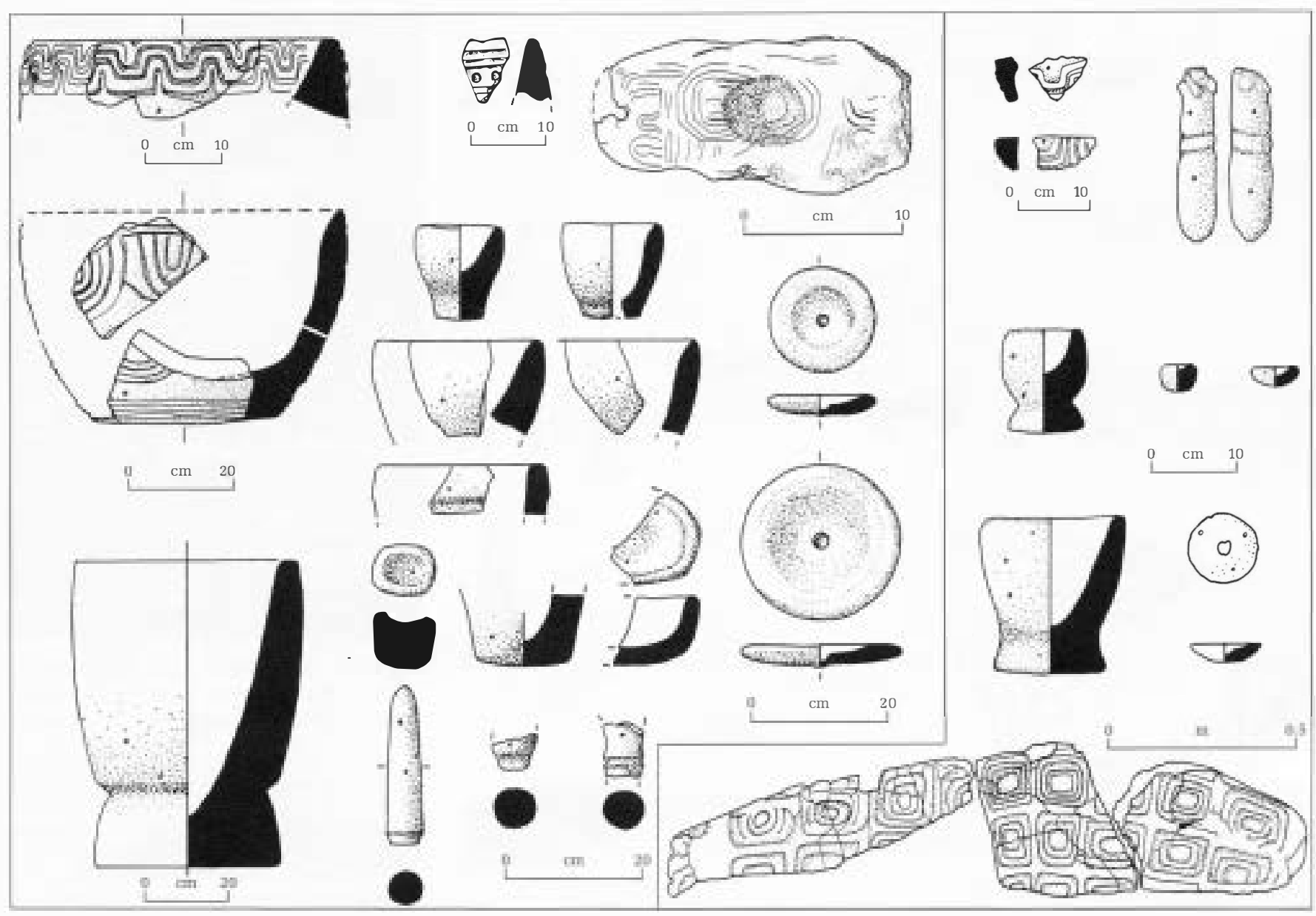

Figure 3 Natufian ground stone artefacts. Bowls, mortars, shallow discs and pestles from (left side) 'Ain Mallaha, Israel; (right side) Wadi Hammeh 27, Jordan (including the decorated wall slabs bottom right). Note the care taken to decorate some of the bowls and mortars, a suggestion of social ritual associated with these artefacts. For further information on sources see p. 93 in Wright 2000(n. 1).

in Natufian sites, are considerably more frequent in PPNA sites. ${ }^{21}$

\section{Kitchen and cupboard: the Pre- Pottery Neolithic B}

Areas of food-related activity were relatively unspecialized in the Natufian and the PPNA, and boundaries between houses and communal spaces seem to have been fluid. During the two millennia of the PPNB (9000-6950 BC) this situation changed profoundly. In the Early and Middle PPNB there is evidence that food preparation was governed by much more structured spatial

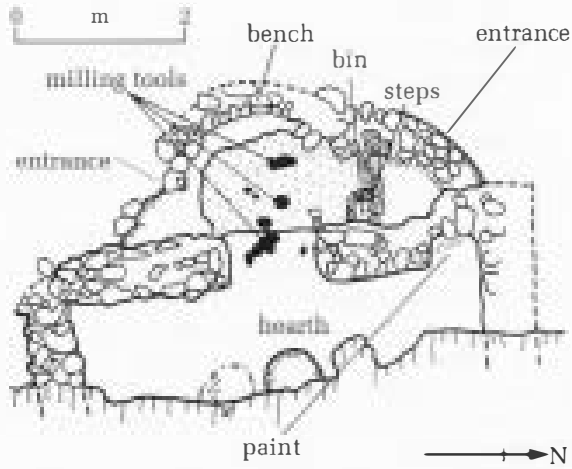

Figure 4 A Middle PPNB house porch at 'Ain Ghazal, Jordan (redrawn from Rollefson \& Simmons 1984, n. 22). rules. Milling, cooking and storage now took place in areas near house entrances, a border zone between community space and the individual household (e.g. Fig 4). ${ }^{22}$ These activities became highly visible and public, affording opportunities for social contacts between households. Nevertheless, individual households appear to have continued to control their own facilities for food preparation and storage, and meals were probably centred on the household. In the Late PPNB, intensification and privatization of storage, milling, cooking and dining seem to have taken place, and these activities became more secluded from the village as a whole (Fig. 5).

The PPNB as a whole was a period of technological innovation in food preparation. ${ }^{23}$ Detailed studies of PPNB groundstone artefacts show that these tools are more diverse in form than the PPNA versions. Large milling tools (grinding slabs and handstones) dominate PPNB foodprocessing equipment (Fig. 6). Many of them are considerably larger than their PPNA counterparts and would have permitted cooks to process more food in a given operation. Many grinding slabs were so large and heavy that they were essentially immovable. For example, the mean weight of 26 complete grinding slabs from the village site of Beidha in southern Jordan was $26.74 \mathrm{~kg}$; some slabs weighed as much as $52 \mathrm{~kg}$, and some slabs were set into floors as fixed features. The handstones used with these slabs vary from small discshape tools that could be operated with one hand, to large oval and loaf-shape handstones that demanded the use of two hands and weighed up to $2.5 \mathrm{~kg}$. PPNB groundstone tools also include small mortars and pestles, and limestone pebbles with cup-holes (often with carbon residues on the interior and possibly used as lamps).

Vessels, usually made of limestone but sometimes of basalt, are of much finer workmanship and are more diverse in size and shape than those of the PPNA. They are simple, well made and usually undecorated (Fig. 7). They are typically simple bowls or platters that lack spouts, handles or lids. Platters are a PPNB innovation and they are the most abundant type of vessel, especially in the Middle and Late PPNB. At Beidha, 34 of the 73 stone vessels found were platters. They are large and shallow, oval or rectangular in plan, of ten with thin walls. They range in diameter from $30 \mathrm{~cm}$ to $1 \mathrm{~m}$ and could hold more food at one time than most PPNA bowls. The smaller platters would have been portable, but 

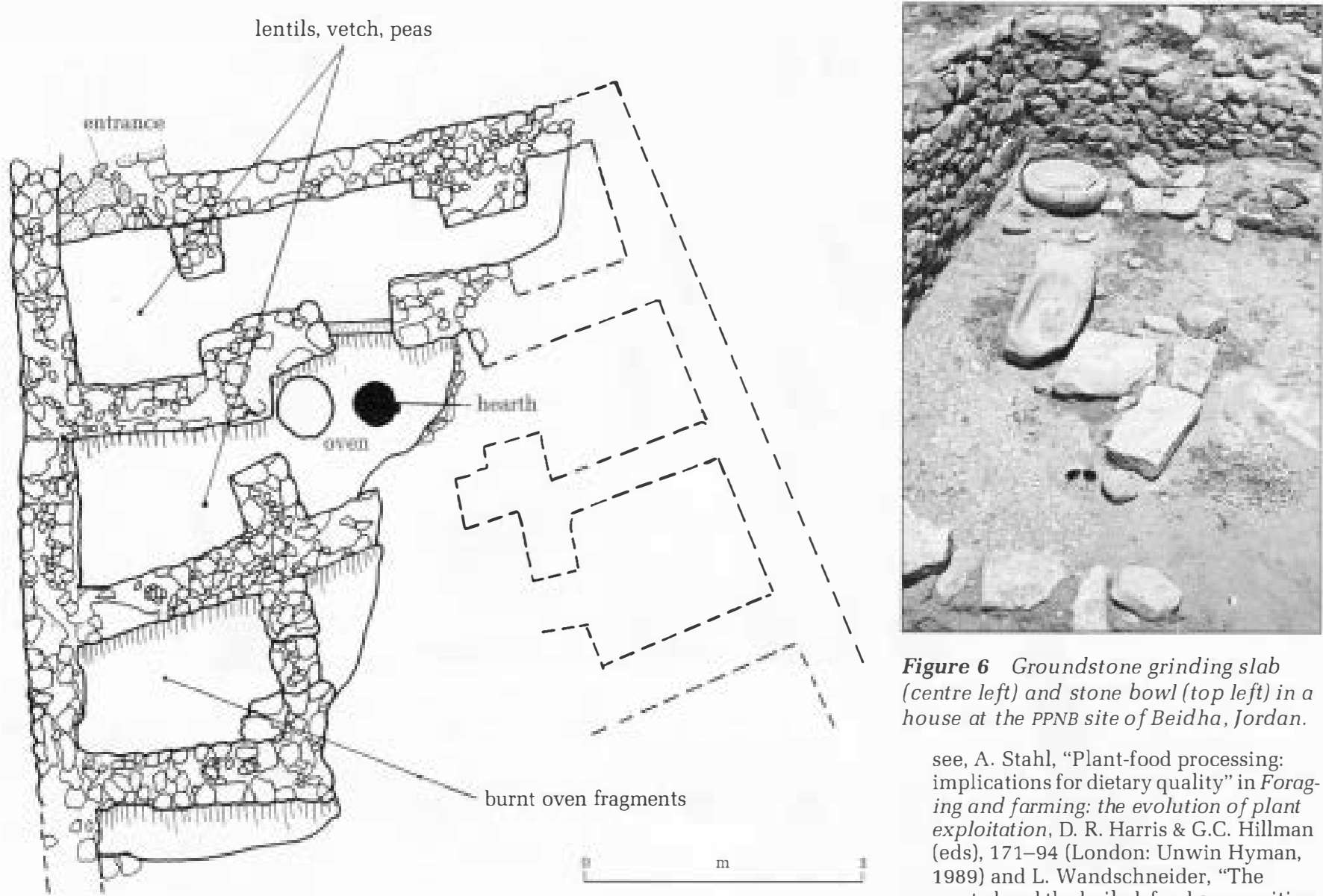

Figure 6 Groundstone grinding slab (centre left) and stone bowl (top left) in a house at the PPNB site of Beidha, Jordan.

see, A. Stahl, "Plant-food processing: implications for dietary quality" in Foraging and farming: the evolution of plant exploitation, D. R. Harris \& G.C. Hillman (eds), 171-94 (London: Unwin Hyman, 1989) and L. Wandschneider, "The roasted and the boiled: food composition and heat treatment with special emphasis on pit-hearth cooking", Journal of Anthropological Archaeology 16, 1-48, 1997.

Figure 5 A Late PPNB house at 'Ain Ghazal (redrawn from Rollefson 1997, n. 24)

those from Beidha weigh between $5 \mathrm{~kg}$ and $10 \mathrm{~kg}$ and are unlikely to have been transported very far, if at all. A few of the platters at Beidha had traces of burning on the exterior base and were probably used in cooking. Other PPNB vessels were made of cordage, basketry (sometimes with waterproof asphalt linings), wood, plaster and early versions of pottery.

In the Late PPNB, some villages grew to unprecedented sizes of 12-15 ha. Houses, often with two storeys and complex plans, reached $160 \mathrm{~m}^{2}$ in area, as much as four times larger than those of the Early PPNB. ${ }^{24}$ There is also evidence of larger assemblages of milling tools per house and of more specialized cooking facilities such as closed ovens, mealing bins (pits and stone installations designed to hold grinding slabs in place); plaster vessels and experiments with pottery making. Food preparation within houses was more secluded and sometimes took place in specialized rooms that functioned as kitchens. Storage facilities become larger and more elaborate, and sometimes occupied whole rooms. All these changes testify to intensified production of prepared foods for larger groups of people. The houses were larger and more complex and there was an increasing emphasis on privacy, including the concept of private property.

\section{Conclusion}

Our knowledge of the technologies and social and cultural dimensions of food preparation in early prehistoric times is still very limited. But the evidence briefly described here, especially that derived from study of the groundstone artefacts, shows that significant changes in cooking and dining took place in Southwest Asia through the many millennia from the Palaeolithic to about $7000 \mathrm{BC}$ - before the development and spread of pottery production later in the Neolithic added a revolutionary new technology to the means availablefor storing, preparing and serving food.

\section{Notes}

1. See K. I. Wright, "Early Holocene ground stone assemblages in the Levant", Levant xxv, 93-111, 1993; "Ground-stone tools and hunter-gatherer subsistence in Southwest Asia: implications for the transition to farming", American Antiquity 59, 238-63, 1994; and "The social origins of cooking and dining in early villages of western Asia", Proceedings of the Prehistoric Society 66, 89-121, 2000.

2. 2. C. Levi-Strauss, The rawand thecooked (London: Jonathan Cape, 1964).

3. 3. J. Goody, Cooking, cuisine and class (Cambridge: Cambridge University Press, 1982).

4. For further discussion of food processing

5. Many archaeologists use the term

"hearth" to refer to any evidence for repeated use of fire, but it is more helpful to distinguish between ancient fire features according to their construction and the frequency of their use. Seven types of fire feature can thus be distinguished: - firepatches: flat patches of fired earth representing single burning events or lacking evidence of repeated burning

- fireplaces: flat patches of earth, repeatedly burned, with burnt soil and ash, but no stones on them

- firepits: hollowed out depressions with burnt deposits and ash, but no stones in the fill or at the edges

- stone-bordered fireplaces: repeatedly burned fireplaces with stones marking the edges

- stone-filled pit hearths: firepits with stones or pebbles inside them for distributing heat or supporting items to be heated

- stone-bordered pit hearths: firepits with stones around the upper edges

- stone-lined pit hearths: firepits with stone slabs lining the whole interior.

6. It has been suggested by Richard Wrangham (in R. Wrangham, J. Jones, G. Laden, D. Pilbeam, N.Conklin-Brittain, "The raw and the stolen: cooking and the ecology of human origins", Current Ant hropology 40, 567-94, 1999) that some sites in

Africa, dated to about 1.6 million years ago and later, display evidence for control of fire by Homo erectus, and firepatches also occur at Lower Palaeolithic sites in 

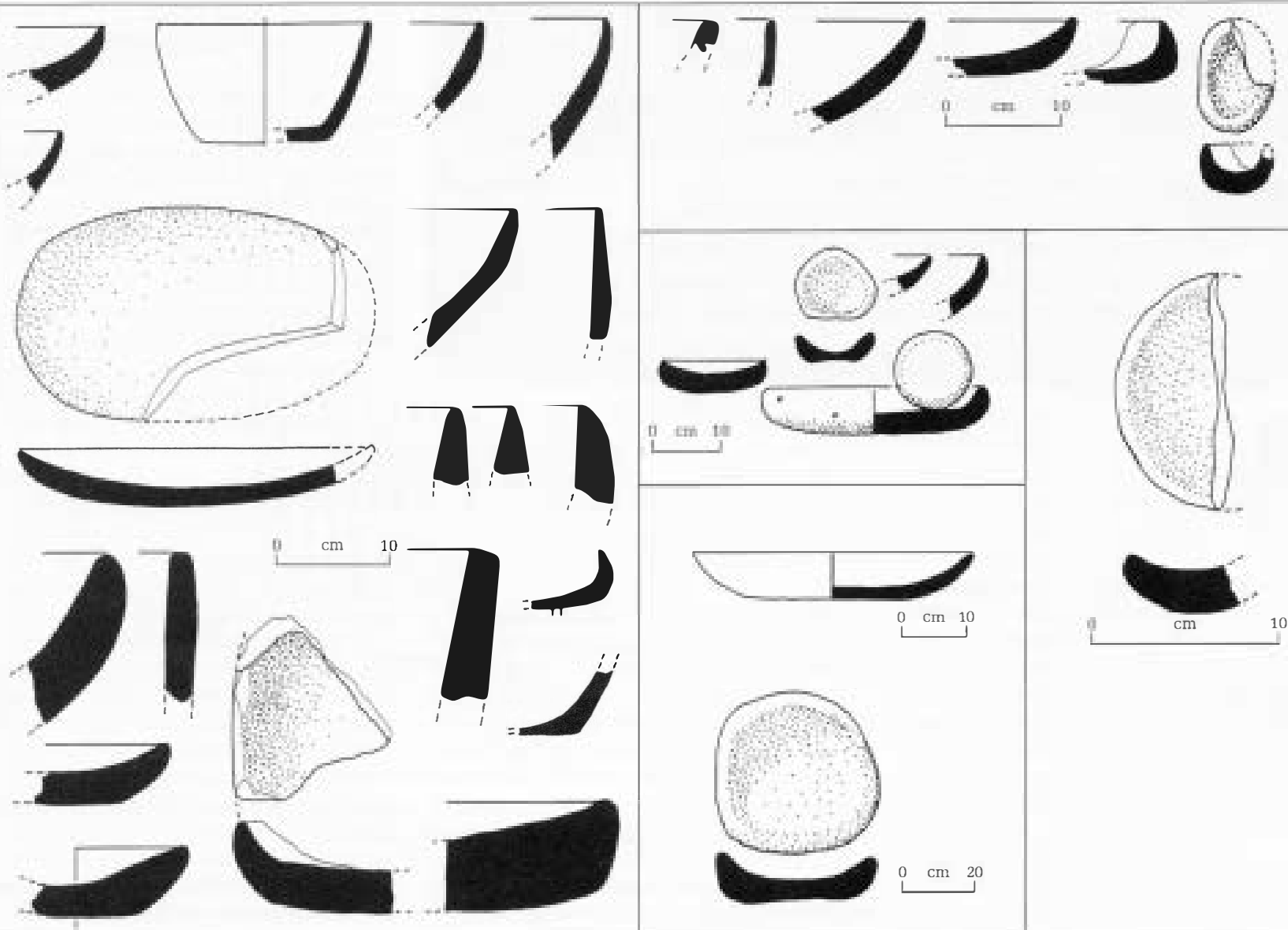

$\underbrace{0} \mathrm{~cm} \quad 20$

Figure 7 PPNB stone vessels. Limestone platters and bowls, including (central section) a grinding bowl with a disc-shape hand stone. For further information on sources see p. 106 in Wright 2000 (n. 1).

China (Zhoukoutien), Hungary

(Vertesszöllös) and Britain (Beeches Pit). But all these tantalizing hints are ambiguous: the fire features and burnt material are not all in situ and some cannot definitely be linked to human activity. In Southwest Asia, no firm evidence for fire control has been found at Lower Palaeolithic sites.

7. Early fireplaces have been discovered at Middle Palaeolithic sites in France, Israel, Jordan, Lebanon, Syria, Turkey, Iraq and Iran; see for example S. James, "Hominid use of fire in the Lower and Middle Pleistocene", Current Anthropology 30, 1-26, 1989.

8. See pp. 393-5 in C. Gamble, The Palaeolithic societies of Europe (Cambridge:

Cambridge University Press, 1999). Concerning the use of heated pebbles placed inside whole animals, see p. 44 in F. McCarthy, Australia's Aborigines: their life and culture (Melbourne:Colorgravure Publications, 1957)

9. See p. 15 in A. Garrard, A. Betts, B. Byrd, C. Hunt, "Prehistoric environment and settlement in the Azraq Basin: an interim report on the 1985 excavation season", Levant XIX, 5-25, 1987.

10. See p. 480 in J. Phillips, "The Upper Palaeolithic of the Wadi Feiran, southern Sinai", Paléorient 2, 477-82, 1988.

11. For discussion of the meaning of feasting, see B. Hayden, "Fabulous feasts: a prolegemon to the importance of feasting", in Feasts: archaeological and et hnographic perspectives on food, politics and power M. Dietler \& B. Hayden (eds), 23-63 (Washington DC: Smithsonian Institution Press, 2001).

12. See Wandschneider 1997 (n. 4 above).

13.See figure 3 on p. 241 in Wright 1994 (n. 1 above).

14. See p. 176 in M. Stekelis \& O. Bar-Yosef, "Un habitat du Paléolithique supérieur à Ein Guev (Israel). Note préliminaire", L'Anthropologie 69, 176-83, 1965.

15. See D. Nadel, "The organization of space in a fisher-hunter-gatherer's camp at Ohalo II, Israel" in Nature et culture, M. Otte (ed.), 373-88 (Liège: University of Liège, 1996)

16.J. Perrot, "Le gisement natoufien de Mallaha (Eynan), Israel”, L'Anthropologie 70, 437-84, 1966.

17. See p. 93 in Wright 2000 ( $n .1$ above). 18. See Perrot 1966 (n. 16 above).

19.O. Bar-Yosef \& A. Belfer-Cohen, "From sedentary hunter-gatherers to territorial farmers in the Levant", in Between bands and states, S. Gregg (ed.), 181-202 (Carbondale, Illinois: Center for Archaeological Investigations, 1991).

20. See p. 94 in Wright 2000 ( $n .1$ above).

21. See pp. 98-101 in Wright 2000 (n. 1 above).

22.G. Rollefson \& A. Simmons, "The 1983 season at 'Ain Ghazal: preliminary report", Annual of the Department of Antiquities of Jordan 28, 13-30, 1984.

23. See pp. 101-112 in Wright 2000 (n. 1 above).
24.G. Rollefson, "Changes in architecture and social organization at 'Ain Ghazal" in The prehistory of Jordan II: perspectives from 1997, H. Gebel, Z. Kafafi, G. Rollefson (eds), (Berlin: ex oriente, 1997. pp. 287-307. 